\title{
Language Acquisition in Early Childhood
}

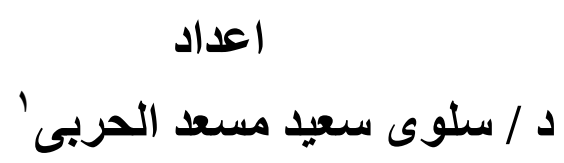

\begin{abstract}
The paper focuses on the process of language development and acquisition in early childhood, and it gives a brief overview of the theories of language development. The paper then concludes with an explanation of the importance of overexposure for early second language acquisition and question whether language learning could turn into a language acquisition after the Chomskian 'critical period.
\end{abstract}

Keywords: Language, early childhood, acquisition, second language acquisition, critical period

أستاذ مساعد علوم أسرية / نمو طقل - كلية التربية - رياض أطفال - جامعة جازان - المملكة العربية السعودية 1 


\section{Introduction}

Human language development relates not just to physical growth but also to mental development (Berger, 1994). Therefore, its growth connotes the physical growth, otherwise, individuals would have a developmental disorder or developmental delay if their mental development is not in the same progression as their physical development (Berger, 1994). Thus, the study of language development, for the most part, can be compared to that of the physical organ and this has become apparent after the Chomskian revolution.

Noam Chomsky concluded that there is a language acquisition device in the human brain, an organ that grows and develops and matures around age 12 years old and then it starts to diminish and withers away, hence we have a 'critical period' (Beger, 1994). As such, this factor has to be taken into consideration in studying language development in children, hence there is a distinction between language acquisition and language learning. Acquisition, and it gave acquisition greater importance than learning. Most importantly, researchers favored language acquisition over learning noting that the early years played a significant role in an individual's ability to achieve high linguistic competence because a language learner, even if he/she reaches perfect competence in his/her L2, still has imperfections, at least in her phonological competence (Bochner and Jones, 2003; Spada and Lightbown, 2004; Yule, 1985). 


\section{Theoretical Background}

According to behaviorist psychology, language is a behavior. The behaviorists followed the empirical method of John Locke, 1690), positing that the mind at birth is a blank slate that is impacted by impressions from experiencing the external world. Thus, an individual is virtually conditioned by his or her environment. From this perspective, we see that human cultures are geographically determined, and language development is merely a child's imitation of his or her surroundings (Bochner and Jones, 2003).

However, the child produces the linguistic sounds of the environment in which he/she lives (which determines the behaviorist side). Also, children are creative with language. According to Bochner and Jones (2003), they adopt the sound patterns that are spoken in their community and form it to express certain concepts that can be seen as novel. The linguistics sounds are utilized to produce an unlimited number of sentences. Then, the child produces sentences that he/she has never heard before. Therefore, there must be something beyond the idea of environmental influence.

Bochner and Jones (2003) noted that the innatists may take a position on the opposite extreme and claimed that human being born with knowledge already inside of us. Plato, for example, referred to the doctrine of recollection; namely, in life we remember knowledge that we saw in previous lives. Hence, the mind's eye sees things in the same way that one realizes or recognizes the intricacies of a mathematical or geometrical problem. Descartes took us through his method of doubting that the knowledge of God is built into our being and thus ideas already exist in the brain (Bochner and Jones, 2003).

However, this may totally negate the influence of experience and how a person's experiences in life may directly affect one's judgment, and the so-called "wisdom". 
Additionally, sensory experience as well as intellectual reflection acts as the essence of the person's character. Here Noam Chomsky's theory ticks in. He did not negate the role of culture nor the human mind's innate capability. They work hand in hand to help bring the human being into full command of his/her linguistic capability (Yule, 1985).

According to Yule (1985), Chomsky (2006) claimed that the brain has a linguistic organ, like any other organ, that grows stronger with training. Chomsky referred to it as the 'language acquisition device'. By way of summation, according to the behaviorist (e.g., Skinner, 1957), children learn language through reinforcement and association, whereas Chomsky took the view that children have an inborn capacity for language understanding and use. And, although there is an innate universal linguistic structure (i.e., "universal grammar"), culture furnishes the child with the vocabulary and the particular language grammatical structures of that particular language.

The most distinctive print of a culture has been defined as its language. Language is a definitive means of its culture; it is the glasses through which the culture conceives of the world around it. Language is passed on from one generation to the next. Very early in life, individuals acquire a language form within a culture with other speakers, often while sitting on his or her mother's knees (Yule, 1985). Acquisition of a child's first language begins at birth and continues to puberty (the 'critical period'). Spada and Lightbown (2004) noted that during the first three years of the child's life, the child gets exposed to the language in his/her environment. During that time child put his or her 'language faculty' into operation. Exposure means that the children are physically immersed in a particular linguistic environment where they can continually hear, interact and 
communicate in that particular language. Notably, interaction has a significant role in language acquisition.

Language is a social phenomenon, so it follows that linguistic development and maturity cannot be considered separately from development and maturity in a much broader sense, as an aspect of social and cultural maturity (Kress, 1985, p. 135).

Language is a social phenomenon. According to Spada and Lightbown (2004), children can also be exposed to the language through audio-visual media, but that exposure is without interaction, but without using the language to express themselves, the children cannot acquire that particular language. In the process of acquisition, children are not offered any instructions on how to speak the language, but rather they are actively constructing possible ways of using the language to which they are exposed, and testing what they come up with to see if it works. By this active process, the children build their own language that conforms with the language that the adults around them are using. Therefore, the child's mind is not a blank slate that gets filled by the environment, children's language is not a copy of what they hear around them and try to imitate. Clearly, a language consists of a limited number of sounds, but with those sounds we can produce a truly infinite number of utterances (Snow and Hoefnagel-Höhle, 1978). So, there are many sentences that children come up with that they never heard before. According to Snow and Hoefnagel-Höhle (1978), by the time a child enters school, he/she becomes a sophisticated language user. Even the muscles that control the articulation organs have been trained to function in a culturally specific way. At this time, the Chomskian acquisition device starts to wane, and at around age 12 , in theory, a child cannot acquire another language - he/she only can learn a second/foreign language. 
Language Acquisition in Early Childhood

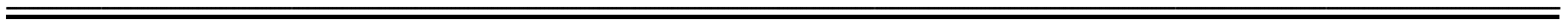




\section{Literature Review}

The ability to use language is innate. Children communicate first by using different languages, such as body language, sign language and oral language. Research has shown that children are active listeners starting in the womb. According to Berger (1994), "language skills begin to develop as babies communicate with noises and gestures and then practice babbling" (p. 169). Speaking ability is acquired in childhood. It happens without teaching. In fact, spontaneous use of language babble is so that children spontaneously before they can even utter words. There is an innate predisposition for vocalization. This is the first stage of language where children babble and coo according to Tomasell and Bates (2001), just to exercise the articulatory organs in an experimentally random and playful manner. Exposure is an important part of getting a child to start using the language of his or her environment. Therefore, the child in this stage is an active listener and observer. The language that the parents use is the primary linguistic environment form which the child acquires her language. Additionally, Piaget believed that cognitive development comes before linguistic production. Therefore, the first words the child learns are those that directly relate to the child's sensory experience and connect the child to his or her exploration of the environment (Berger, 1994).

According to Lieven and Tomasello (2008), the second stage is when the child starts to babble in a pattern similar to the patterns of adult speech, this happens between the ages of six to nine months. Then, it is a matter of uttering sounds. At first, what predominates are nasal $/ \mathrm{m} /, / \mathrm{n} /$ and $/ \mathrm{ng} /$ as well as the voiced stops $/ \mathrm{b} /$, /d/ and /g/. Notably, these are the sounds that babies use in their babbling stage. Moreover, the vowel /a/ is the first sound to be mastered since it is the sound the 
baby utters when crying, then babies tend to master the nasal stops since they are easy for babies to perceive.

Furthermore, Lieven and Tomasello (2008) noted that the one-word stage, where babies use only one word (including made-up words) to refer to random things and, at times, to substitute for a complete sentence. This stage is around age 1 when concrete words (e.g., 'car' and 'eat') emerge. For example, babies in this stage may imply "I am hungry" by saying "eat". A baby at this stage can obey simple commands, such as "no". At this stage, Prathanee et al. (2008) remarked that the child identifies family members and familiar objects by name, and imitates familiar noises like cars, planes and birds. Also, they are able to utter few words and look at a person who is talking and if reminded say "hi" or "bye". Babies in this stage are also able to use expressions like "Oh-oh," ask for something by using one word or pointing to it and identify an object in a picture.

Moreover, according to Lieven and Tomasello (2008), by the age of 1 year and 8 months, the two-word stage begins, wherein the child begins to represent an entity with two words, albeit without morphological and syntactic markers.

Nevertheless, we can notice that a word order is often used. For example, the utterance "dada chair" could mean "dad is sitting on the chair," "that's my dad's chair" or "Dad, could you put me on the chair?"

In addition, Lieven and Tomasello (2008) added that the telegraphic stage occurs between the ages of $2-2 \frac{1}{2}$ years. In this stage, the child uses what is identifiable as a rudimentary sentence, or rather a word series without grammar. For example, a child may say to her mother "I good girl." Grammar is an abstraction and children acquire the concrete terms first. Moreover, at this stage, it is noted that the child may only say about 50 words, but can actually understand many more. According to Tomasello and Bates (2001), the child will now echo single words that are 
spoken by someone else and talk to himself or herself and jabber expressively. The child may say names of toys and familiar objects, uses two- to three-word sentences like "Daddy bye-bye," or "All gone." In this stage, a child may hum or try to sing simple songs, and listen to short rhymes or finger plays. They may even point to their eyes, ears, or nose when asked and, they can usually use the words "bye," "hi," "please," and "thank you" if prompted by an adult.

By age two, the child is able to produces most of the consonants (Lieven and Tomasello, 2008). Therefore, a child at this stage will render words using unique phonological processes, what Shipley (2004) characterized as occurrence of predictable phonological errors or deviations, when trying to imitate the adult's sound system:

Voicing: "A voiceless sound is replaced by a voiced sound." For example, /p/ is replaced by $/ \mathrm{b} /$, and $/ \mathrm{k} /$ is replaced by $/ \mathrm{g} /, \mathrm{t} /$ is replaced by $/ \mathrm{d} /$, or $/ \mathrm{f} /$ is replaced by /v/. For example, [pig]à[big], [car]à[gar].

Word-final devoicing: "A final voiced consonant in a word is replaced by a voiceless consonant. /d/ has been replaced by /t/, and /g/ has been replaced by /k/." For example, [red]à[ret], [bag]à[bak].

Final consonant deletion: "The final consonant in the word is omitted". For example, in [home], $/ \mathrm{m} /$ is left out.

Velar fronting: "A velar consonant is replaced with a consonant produced at the front of the mouth. Hence, $/ \mathrm{k} /$ is replaced by $/ \mathrm{t} /, / \mathrm{g} /$ is replaced by $/ \mathrm{d} /$. For example, [kiss]à[tiss], [goat]à[doat].”

Palatal fronting: "The fricative consonants /sh/ is replaced by fricatives that are made further forward on the palate /s/." For example, [shoes]à[soes]. Gliding of liquids: "The liquid consonants /l/ and /r/ are replaced by /w/ or 'y"'. For example, [run]à[wun]. 
Stopping: A “fricative consonant (/f//v//s//z/, 'sh', 'zh', 'th' or /h/), or an affricate consonant ('ch' or $/ \mathrm{j} /$ ) is replaced by a stop consonant $(/ \mathrm{p} / / \mathrm{b} / / \mathrm{t} / / \mathrm{d} / / \mathrm{k} /$ or $/ \mathrm{g} /)$." For example, [jump]à[dump].

"Phonological processes describe what children do in the normal developmental process of speech to simplify standard adult productions" (Shipley, 2004). The phonological process compares a child's articulatory production to that of an adult. Therefore, the advantage of using this approach is the way in which it measures the development of the child according to his or her lifespan. This method primarily helps speech language pathologists to diagnose a child's speech developmental delay (Shipley, 2004).

In addition to the child's unique use of phonological aspects of language, in the morphological level of language, the child is also creative in linguistic use, confirming the innate linguistic capability advocated by Chomsky. According to the Chomskian (2006), view children learn the "superficial" grammar of a specific language because all human languages share a basic and a "deep structure" of universal grammatical rules that connotes to the innate capability of the human brain. Stages in the acquisition of a first language, according to Snow and Hoefnagel-Höhle (1978); Tomasello and Bates (2001), may be assessed by the originality and complexity of a child's utterances. Therefore, children first start by over-generalizing the rules. For this stage, the child starts processing the rules of language. Production of words including [feets] or [foots] instead of [feet], overgeneralizing the rule for making plurals or [goed] instead of [went], overgeneralizing the past tense form according to its regular conjugation. This shows a process of development to full competence of the language use leading them to understand the exceptions to the rules. 


\section{Conclusion}

In conclusion, acquiring language is a natural way of speaking it. It is a process where the language grows organically in the child's mind rather than artificially constructing it in the process of learning (Berger, 1994). Thus, the difference between acquisition and learning is the same difference between a tree that grows naturally in its natural habitat and a building that is clearly manmade and imposed into an environment. Therefore, childhood is the optimum age to acquire a language (Berger, 1994; Lieven and Tomasello, 2008; Yule, 1985). As it is practically observed, a person who acquires a language is always more fluent than one who learns it. Second language acquisition is what the learner is aiming for, but acquiring the language after the critical period is a very difficult and conscious endeavor because there is constant interference from the first language, with which the learner is more competent and comfortable than the target language (Snow and Hoefnagel-Höhle, 1978). Since one's language acquisition device is very active in the early years of life, childhood years are the best time to acquire languages. A person will not have only first and second (foreign) languages, he/she would have more than one first language since they are all acquired at the same time (Yule, 1985).

Children of immigrants to the United States acquire both the first language and second language (English) through early exposure. They receive a good dose of exposure to their native language in their familial environment. Similarly, they receive a good dose of exposure to English in school and in communicative 
situations with their English-speaking classmates and friends. Linguists refer to a child's exposure to a different linguistic environment as submersion, which implies that one or two children are learning a foreign language, the first language for the rest of the class, by over-exposing them to it.

Unlike the process of acquisition, where the child spontaneously and gradually develops his or her linguistic competence, the learning process involves a student consciously trying to accumulate knowledge of vocabulary and grammar in a controlled environment, i.e., the classroom. Mostly, they tend not to develop the same level of proficiency in the new language as those who acquire it. This is due to the interference of their first language. In fact, there are students who achieve great experience in reading and writing that surpasses the ability of native speakers, but not in speaking, which is the phonological aspect of a language (Yule, 1985).

Taking into consideration the theory of language acquisition along with the idea of the critical period of language acquisition, one could see that it is impossible for the language learner to achieve true fluency. The question, though, is whether Chomsky is completely correct about this language acquisition device and its early death or if there is a way to offset its death so that language learning can indeed be a process of language acquisition.

There is no disagreement about the effectiveness of early language acquisition, but what if the language learner has a positive attitude towards the culture in question. Positive attitudes produce motivations in the students. "The 
overall findings show that positive attitudes and motivation are related to success in second language learning, [and consequently acquiring a second identity]" (Spada and Lightbown, 2004). There are two kinds of motivations at issue in this process:

1. Curiosity: A desire to understand a group of people and their way of life; a desire or interest to know why a group of people do things differently from us, or why they believe in so many things that we have never considered.

2. Empathy: Upon repeated exposure, one might come to the conclusion that this group of people has a more sensible handle on things than we do.

While the first type of motivation leads to language learning for more immediate or practical goals, the second type leads to more successful language learning. It leads to personal growth and cultural enrichment. With the second kind of motivation, the learner goes through less cultural shock because he/she already possesses some background knowledge about the target culture. He/she is going to have an uncanny love for the target culture. This leads students to try identifying with the target culture and thereby pushes them to assimilate with the target culture. 


\section{References}

Berger, K. (1994). The developing person through the lifes pan ( $3^{\text {rd }}$ ed.). New York:

Worth Publishers.

Bochner, S., \& Jones, J. (2003). Child language development: Learning to talk ( $2^{\text {nd }}$ ed.).

London: Whurr Publishers.

Chomsky, N. (2006). Language and mind (3th ed.). New York, NY: Cambridge University Press.

Kress, G. (1985). Socio-linguistic development and the mature language user:

Different voices for different occasions. Wells, G \& Nichollas, J (Eds.), Language

\& learning: An interactional perspective. (pp. 135-150). London and Philadelphia: Falmer Press.

Lieven, E., \& Tomasello, M. (2008). Children's first language acquisition from a usage-based perspective: Handbook of cognitive linguistics and second language acquisition. New York, NY: Routledge Taylor \& Francis Group.

Locke, J. (1690) An Essay Concerning the Human Understanding; eBook of Gothenburg University.

(www.ub.gu.se) Publication: Raleigh, N.C. Alex Catalogue

Prathanee, B., Pongjanyakul, A., \& Chano, J. (2008). Thai speech and language test for children between 1 and 2 years of age. International Journal of Language \& Communication Disorders, 43(1), 125-140. Retrieved from http://search.ebscohost.com/ 
Shipley, K. (2004). Assessment in speech-language pathology: A resource manual. Australia; Clifton Park, NY: Delmar Learning.

Skinner, B. F. (1957). Verbal Behavior. New York: Appleton-Century-Crofts.

Snow, C., \& Hoefnagel-Höhle, M. (1978). The critical period for language acquisition: Evidence from second language learning. Child Development, 49(4), 1114-1128. doi:10.1111/1467-8624.ep10713138

Spada, N., \& Lightbown, P. (2004). How languages are learned. Oxford:

University

Press.

Tomasello, M., \& Bates, E. (2001). Language development: The essential readings. Malden, MA; Oxford, UK: Blackwell Publishers.

Yule, G. (1985). The study of language. New York: Cambridge University Press. 